\title{
High-performance Activated Carbons Prepared by KOH Activation of Gulfweed for Supercapacitors
}

\author{
Shijie $\mathrm{Li}^{1}$, Kuihua Han ${ }^{1, *}$, Pengchao $\mathrm{Si}^{2}$, Jinxiao $\mathrm{Li}^{1}$, Chunmei $\mathrm{Lu}^{1}$ \\ ${ }^{1}$ School of Energy and Power Engineering, Shandong University, 250061 Jinan, PR China \\ ${ }^{2}$ School of Material Science and Engineering, Shandong University, 250061 Jinan, PR China \\ *E-mail: hankh@163.com
}

doi: $10.20964 / 2018.02 .08$

Received: 26 September 2017 / Accepted: 24 November 2017 / Published: 28 December 2017

\begin{abstract}
Activated carbons with huge specific surface area and developed pore structure are prepared by $\mathrm{KOH}$ activation of gulfweed. Six kinds of gulfweed-based activated carbons with different specific surface area are selected to investigate their electrochemical performance and the influence of specific surface area on the electrochemical performance. The electrochemical performance is investigated by galvanostatic charge-discharge and cyclic voltammetry test. The highest gravimetric capacitance is demonstrated by $\mathrm{AC}_{3155}$, and the capacitance value reaches up to $395 \mathrm{~F} \mathrm{~g}^{-1}$ at the current density 0.05 $\mathrm{A} \mathrm{g}^{-1}$ in $6 \mathrm{M} \mathrm{KOH}$. Moreover, a slow fading of capacitance is observed as the current density increase. The capacitance retention is $92 \%$ after 10000 cycles at the current density $2.5 \mathrm{~A} \mathrm{~g}^{-1}$. The gulfweedbased activated carbons demonstrate both excellent high rate capacitive performance and cycle performance.
\end{abstract}

Keywords: Gulfweed-based activated carbon; Specific surface area; Supercapacitors; Electrochemical performance.

\section{FULL TEXT}

(c) 2018 The Authors. Published by ESG (www.electrochemsci.org). This article is an open access article distributed under the terms and conditions of the Creative Commons Attribution license (http://creativecommons.org/licenses/by/4.0/). 